\title{
NARRANDO O ÍNDICO \\ Contrapontos entre paradigmas críticos e representações: João Paulo Borges Coelho e M.G. Vassanji
}

\author{
Elena Brugioni \\ Universidade do Minho, Portugal
}

Resumo: A partir de uma leitura da obra literária de João Paulo Borges Coelho (Moçambique) e M.G. Vassanji (Tanzânia-Quénia-Canadá) propõe-se uma reflexão em torno de cartografias e paradigmas críticos que pautam o cânone das chamadas Literaturas Africanas. Procurando responder às solicitações propostas pelos próprios textos literários - e, logo, aos desafios enfrentados, hoje em dia, pela crítica humanística - o oceano Índico destaca-se como um paradigma transnacional específico, cuja articulação crítica e epistemológica parece deixar em aberto um conjunto de itinerários disciplinares e operacionais indispensáveis para repensar a abordagem às representações literárias e, logo, os seus significados.

Palavras-chave: Literaturas Africanas; Estudos Culturais; Oceano Índico; Paradigma transnacional; João Paulo Borges Coelho; M.G. Vassanji.

A necessidade de repensar espaços, tempos e relações no que vem sendo definido como pós-colonialidade sugere a ocorrência de paradigmas críticos e epistemológicos alternativos e indispensáveis para uma leitura "situada" (Hall, 1990) e "mundana" (Said, 2004) das práticas e das linguagens de representação na contemporaneidade global. $\mathrm{O}$ apelo a $\mathrm{H} /$ histórias e lugares heterogéneos que as mesmas representações literárias parecem conter e invocar obriga a uma redefinição matricial de sujeitos, temas e problemas que pautam a literatura, apontando, simultaneamente, para uma reformulação estratégica da crítica humanística.

No que concerne às escritas literárias que se colocam fora de uma dimensão espacial e cultural habitualmente definida como europeia ou - recorrendo a uma definição mais banalizada - ocidental, a ocorrência de cartografias críticas alternativas parece contribuir para uma perspectivação inédita das práticas de representação dentro de uma dimensão contextual mais alargada, proporcionando o surgir de epistemologias e leituras que parecem contribuir para um alargamento significativo da crítica humanística e, logo, do seu campo semântico e operacional. 
No que diz respeito à recepção crítica de autores e textos habitualmente situados nas chamadas Literaturas Africanas, ${ }^{1}$ o recurso a perspectivações contextuais alternativas proporciona a ocorrência de cartografias críticas e contrapontos diversificados, sugerindo, ao mesmo tempo, outros itinerários de leitura destas mesmas representações literárias. Deste modo, por via de abordagens que movem de paradigmas operacionais e disciplinares diversificados surgem diálogos intertextuais entre escritas e autores - geralmente cartografados a partir da sua identidade linguística -, apontando para uma leitura das representações literárias numa dimensão situada e, todavia, transnacional, e logo contribuindo para o reposicionamento da literatura e do(s) seu(s) significado(s) dentro do que vem sendo definido como modernidade global (Appadurai, 1996).

A este propósito, no que diz respeito a uma dimensão disciplinar específica tal como aquela que responde ao chamado cânone crítico das Literaturas Africanas, os Indian Ocean Studies [IOS], ${ }^{2}$ ao operacionalizar a relação entre espaço e história - na senda da reflexão proposta por Fernand Braudel - e logo encarando o mar como um lugar de relações históricas, económicas e também culturais (Braudel, 1985), proporcionam um conjunto de itinerários epistemológicos que configuram o Oceano Índico na perspectiva de uma "arena inter-regional" (Bose, 2006: 6) emblemática onde, também de um ponto de vista cultural, surgem sujeitos, relações e representações específicas e alternativas. De um ponto de vista epistemológico e conceptual, encarando o Oceano Índico não apenas como um "sistema mundo", e logo complexificando a dimensão relacional que caracteriza a abordagem proposta pelos chamados Area Studies, sobressai uma configuração espaço/temporal capaz de conjugar, como afirma Sugata Bose, "a generalidade do sistema mundo" com "as especificidades da dimensão regional" (2002), encarando então o Índico não tanto como um constructo espacial unitário, mas sim como uma rede de relações dinâmicas e estruturadas (Chaundhury, 1990) cuja articulação numa dimensão espaço/temporal específica permite salientar ligações, contactos e dissonâncias entre "mundos" distintos e, todavia, contíguos. ${ }^{3}$ De um ponto de vista cultural e literário, como salienta Isabel Hofmeyr:

\footnotetext{
${ }^{1}$ O recurso à definição de Literaturas Africanas é feito ressalvando os limites críticos e operacionais apontados, a meu ver, por esta categoria; daí a opção pela grafia em itálico.

2 Para uma primeira indicação bibliográfica relativamente aos Indian Ocean Studies veja-se: Bose, 2006; Fawaz \& Bayly, 2003; Kearney, 2004; McPherson, 1993; Moorthy \& Jamal, 2010; Pearson, 2003; Vergès, 2003.

${ }^{3}$ A definição do Índico como "espaço de relações estruturadas" ou ainda como "arena inter-regional” e não na perspectiva de um constructo unitário e homogéneo é fundamental pois proporciona uma reflexão em torno de diferenças, ambiguidades e tensões que se inscrevem neste espaço. Do ponto de vista literário - e, logo, dos imaginários que as chamadas Literaturas do Índico constroem e convocam - salientar esta dimensão fragmentária, diferencial e ambígua torna-se crucial em termos epistemológicos,
} 
(...) temos de pensar o Índico como o espaço por excelência das modernidades alternativas; aquelas formações da modernidade que tomaram forma graças a um arquivo de tradições intelectuais profundas e complexas. (...) Perceber os discursos políticos e as acções torna-se uma tarefa que é desempenhada através da compreensão de arquivos coloniais e pós-coloniais, onde diferentes versões da modernidade são negociadas, num conjunto de idiomas em constante mudança acerca da "tradição". (Hofmeyr, 2007: 13 e ss; tradução minha)

Dentro desta perspectiva operacional específica, algumas propostas literárias contemporâneas africanas parecem apontar para uma cartografia criativa e conceptual que poderá ser abordada por via do que vem sendo definido como "paradigma do Índico" (Hofmeyr, 2007), proporcionando um conjunto de problematizações significativas que se prendem com a relação entre literatura, história e memória. Surge então uma representação literária que se configura na dimensão de um lugar de resgate e questionamento das narrativas históricas ilustradas através de uma problematização em torno da relação entre experiência e objectividade (Sarlo, 2005) que marca esta constelação conceitual.

Em síntese, observando o Oceano Índico como um paradigma crítico e cultural transnacional específico, considerarei a proposta literária de João Paulo Borges Coelho e M.G. Vassanji, procurando reflectir em torno das solicitações que a obra destes autores parece colocar no que concerne a relação entre literatura, história e memória. No entanto, o itinerário que aqui se propõe obriga-me, em primeiro lugar, a uma problematização dos paradigmas que pautam o cânone crítico das Literaturas Africanas, proporcionando uma revisão situada do aparato conceptual e epistemológico que pauta a leitura destas escritas e, logo, caracterizando o Índico como uma possível cartografia alternativa para ler e situar estas representações literárias.

\section{Cartografias Alternativas: o Paradigma do Índico}

No que diz respeito à acção social, o espaço é, a priori, a dimensão fundamental e mais racional de que a ordem cronológica. O espaço é mais relevante, para a compreensão da história, de que ao seu complemento cronológico.

K.N. Chaundhury

Procurando situar o itinerário crítico que me proponho desenvolver, torna-se fundamental considerar algumas especificidades disciplinares que dizem respeito ao cânone crítico das chamadas Literaturas Africanas. Neste sentido, o recurso ao que foi

proporcionando um contraponto entre representações que não se fundamenta apenas em critérios de analogia ou semelhança, mas também de diferença e heterogeneidade. 
definido como paradigma transnacional do Índico obriga a uma breve reflexão em torno das cartografias críticas que marcam este campo de estudo, tornando, deste modo, mais evidentes as potencialidades que o recurso a paradigmas críticos e conceptuais alternativos pode evidenciar, e logo proporcionando um conjunto de solicitações matriciais para a leitura das práticas de representação dentro de uma perspectiva epistemológica pós-colonial.

As cartografias - literárias e críticas - que têm vindo a surgir em função de uma sistematização das chamadas Literaturas Africanas são caracterizadas pela ocorrência de conceptualizações espaciais e/ou linguísticas que se destacam como paradigmas operacionais no que concerne à definição e também à própria produção crítica que marca os chamados Estudos Literários Africanos. Por outras palavras, estas literaturas são frequentemente cartografadas operacionalizando uma categorização espacial de cariz marcadamente político: literaturas nacionais e/ou regionais - Literatura Moçambicana, Literaturas da África Oriental, etc. — ou ainda recorrendo a definições de carácter linguístico - ex. Literaturas Africanas Anglófonas, Francófonas, Lusófonas, etc. - ${ }^{4}$ Ora, estas cartografias são, por vezes, cruzadas, determinando o aparecimento de definições transnacionais, contudo igualmente restritas e, logo, problemáticas que apontam para um conjunto de questões epistemológicas relevantes. 5

A ocorrência de sistematizações deste género torna-se um factor determinante no que concerne aos paradigmas teóricos e, logo, operacionais que pautam a crítica destas literaturas onde temas e problemas parecem, todavia, fundamentados numa perspectivação de matriz nacional e/ou identitária que encara a literatura na dimensão de uma prática de representação que contribui para a construção de um imaginário cultural e político de cariz nacional e hegemónico, caracterizado por uma relação de oposição entre espaço/tempo colonial e pós-colonialidade. Por outras palavras, de um ponto de vista crítico estas cartografias determinam o surgir de especificidades disciplinares que colocam alguns problemas, especialmente tendo em conta as solicitações contidas e apontadas pelos próprios textos literários.

\footnotetext{
${ }^{4}$ Importa reconhecer que as sistematizações que respondem a um critério de identidade linguística parecem muito mais frequentes relativamente àquelas de cariz político, evidenciando um conjunto de problemas relevantes que se prendem com os processos de afirmação e reconhecimento - institucional e cultural - de disciplinas e campo de saberes específicos.

${ }^{5}$ Observando as diferentes obras de sistematização das Literaturas Africanas - tais como, histórias literárias, antologias, etc. - o critério linguístico parece ainda persistente e significativo. A este propósito, e entre os muitos casos que se poderiam citar, veja-se, por exemplo, o que afirma Jessica Falconi relativamente à exclusão da literatura da Guiné Bissau na definição de Literaturas da África Ocidental (Falconi, 2012) ou pense-se ainda na célebre História das Literaturas Africanas e das Caraíbas - The Cambridge History of African and Caribbean Literatures - organizada por Abiola F. Irele e Simon Gikandi, onde as definições temáticas ou as sistematizações regionais e/ou transnacionais parecem, todavia, subordinadas a um critério de definição linguística.
} 
Sobretudo em relação à observação destas escritas a partir da sua "catalogação linguística", surge uma configuração crítica e conceptual que parece apontar para um imaginário de cariz ainda colonial, ou, por outro lado, responder a agendas não imediatamente relacionadas com as fisionomias literárias que caracterizam determinadas práticas de representação. A este propósito, como afirma Antonio Gramsci:

Sempre que aflora, de um modo ou de outro, a questão da língua, significa que se está a impor uma série de outros problemas: a formação e a ampliação das classes dirigentes, a necessidade de estabelecer relações mais íntimas e seguras entre os grupos dirigentes e a massa popular-nacional, ou seja, a reorganização da hegemonia cultural. (Gramsci, 2007; tradução minha)

Por conseguinte, o recurso a outros paradigmas críticos e epistemológicos para uma abordagem das Literaturas Africanas torna-se uma passagem indispensável para responder aos desafios que os próprios textos literários contêm e colocam, contribuindo, ao mesmo tempo, para a desconstrução de categorizações críticas que parecem "assombradas" por uma ideologia ainda colonial, cujas instâncias teóricas e desdobramentos operacionais colocam problemáticas significativas no que diz respeito à leitura de determinadas representações culturais na contemporaneidade.

Para além disso, de um ponto de vista disciplinar, o aparecimento de cartografias alternativas - tal como parece ser a do Índico - fundamenta-se na integração de áreas e campos do saber diversificados, cuja intersecção faculta o surgir de um aparato conceitual e teórico mais articulado. ${ }^{6}$ Por via de novos paradigmas críticos e epistemológicos fundamentados numa dimensão heteroglóssica e transnacional, sobressaem também perspectivações e abordagens que respondem a outros campos semânticos ou operacionais; ${ }^{7}$ a este propósito, pense-se na conceptualização que responde à definição de Literaturas do Índico onde sistemas literários nacionais ou, melhor, autores e textos são observados em vista de uma perspectivação contextual significativa e emblemática, reivindicando a existência de campos de saberes debilmente consagrados por causa de uma recepção crítica fundamentada em conceitos e metodologias ineficazes para ler e situar as solicitações apontadas pelos próprios

\footnotetext{
${ }^{6}$ A este propósito, veja-se o texto de Michael Pearson "History of the Indian Ocean: a Review Essay" (Pearson, 2011) onde o estudioso considera uma variedade significativa de publicações que se situam nos chamados Indian Ocean Studies, salientando abordagens e especificidades disciplinares relevantes em vista de uma reflexão completa e orgânica sobre o Índico.

${ }^{7}$ A este propósito, veja-se: Gupta, Pamila, Isabel Hofmeyr \& Michael Pearson (Eds.) (2010) Eyes Across the Water. Navigating the Indian Ocean. Unisa Press \& Penguin India e Elena Brugioni \& Joana Passos (Orgs.) (2013) Dossier "Narrando o Índico" in Diacrítica - Literatura, 27 (3). Vila Nova de FamalicãoBraga: Húmus Edições-CEHUM.
} 
textos literários num quadro crítico-teórico pós-nacional. Aliás, é sobretudo considerando as solicitações que certas escritas africanas contemporâneas parecem conter e apontar que novas cartografias críticas e aparatos epistemológicos se tornam urgentes e necessários (Garuba, 2009). Por via, por exemplo, de uma categoria como a do Índico que pode representar, como afirma Isabel Hofmeyr, "um novo paradigma para um transnacionalismo do Sul Global no que concerne as relações culturais e literárias" (2007) um conjunto de questões cruciais parecem surgir.

Em rigor, é operacionalizando o "paradigma do Índico" (Hofmeyr, 2007) que as constelações conceptuais que pautam a crítica às Literaturas Africanas - tradição, modernidade, nação, diferença, raça, comunidade, etc. - beneficiariam de uma revisão situada, capaz de desconstruir os processos de "comodificação da diferença" (Ahmad, 1992) que parecem caracterizar várias instâncias de recepção das Literaturas Africanas, ${ }^{8}$ redefinindo, deste modo, o aparato crítico que molda as epistemologias literárias pós-coloniais, e salientando aparatos conceptuais alternativos e, sobretudo, imaginários e repertórios culturais inéditos. ${ }^{9}$

Para além disso, esta revisão conceptual e epistemológica permitiria o surgimento de constelações teóricas diversificadas que, por exemplo, não se fundamentam apenas numa relação de oposição entre colonialidade e condição pós-colonial, e onde um conjunto de diálogos e relações que esbatem as cartografias linguísticas poderiam ocorrer, proporcionando uma revisão situada das especificidades que marcam o campo crítico das Literaturas Africanas e o aparato teórico produzido no seio dos chamados estudos pós-coloniais. ${ }^{10}$

No que diz respeito às chamadas Literaturas Africanas de língua portuguesa, um paradigma como o do Índico facultaria uma perspectivação relacional ainda hoje pouco desenvolvida referente a uma abordagem, por exemplo, da Literatura Moçambicana numa dimensão transnacional, determinando uma redefinição de temas, imaginários, especificidades e problemas que pautam as representações literárias contemporâneas ${ }^{11}$. Trata-se de uma perspectivação que redefine o campo semântico e os repertórios

\footnotetext{
${ }^{8}$ Para uma reflexão crítica em torno dos processos de comodificação das margens que caracterizam a recepção crítica das Literaturas Africanas de língua portuguesa, veja-se Brugioni, 2012a.

${ }^{9}$ No que diz respeito às chamadas Literaturas Africanas de língua portuguesa, a operacionalização do paradigma do Índico parece contribuir para a desconstrução daquilo que Manuela Ribeiro Sanches define como "lusofonia da disciplina" (Sanches, 2007).

${ }^{10}$ Neste sentido, penso, por exemplo, na reflexão proposta por Isabel Hofmeyr sobre a escravatura no Oceano Índico e, logo, na problematização dos conceitos de escravo [slave], colono [settler] e migrante [migrant] que surge dentro desta perspectivação espaço/temporal específica. (Hofmeyr, 2007)

${ }^{11}$ Para uma leitura da poesia moçambicana através do paradigma do Índico, veja-se: Falconi 2008 e Noa 2012.
} 
culturais convocados e apontados por esta literatura, contribuindo, simultaneamente, para uma redefinição da relação entre medium literário e dimensão contextual específica. Neste sentido, como salienta Francisco Noa:

[O] Oceano Índico (...) institui-se como fonte e motivação de diferentes universalismos e modernidades que, de certo modo, desafiam as variantes europeias e ocidentais, sobretudo as que estão inevitavelmente ligadas a processos de afirmação hegemónica. Assim, vemos desenhar-se uma cartografia que vai muito além dos limites fronteiriços sejam eles locais ou nacionais e que apostando na imaginação transcende a "era da territorialidade" (Bose 2006: 277) identitária e cultural que caracterizou o período de afirmação nacionalista. (Noa, 2012)

A este propósito, pense-se, por exemplo, na proposta literária de um escritor como João Paulo Borges Coelho, cuja escrita convoca dimensões espaciais e temporais que redefinem o repertório cultural dito nacional, reposicionando a especificidade de sujeitos e contextos dentro de uma dimensão transnacional emblemática. ${ }^{12}$ É por via de uma relação complexa entre tempo e espaço que a obra literária deste autor aponta para uma dimensão contextual que esbate as fronteiras do espaço nacional, convocando relações e dinâmicas que devem ser observadas através de uma perspectivação que se situa fora de uma cartografia linguística e geográfica apenas nacional. ${ }^{13}$ Aliás, observando algumas das propostas literárias de alguns autores contemporâneos cujas escritas convocam mais ou menos explicitamente o espaço simbólico, cultural e geográfico do Índico, ${ }^{14}$ sobressaem um conjunto de possíveis contrapontos cuja operacionalização proporciona o aparecimento de novas relações entre contextos e representações, facultando a redefinição de questões e epistemologias através das quais são lidas e situadas as escritas literárias contemporâneas. Paradigmas críticos deste género parecem apontar para itinerários teóricos e epistemológicos inéditos e, ao mesmo tempo, cruciais para desmontar as cartografias linguísticas eurocêntricas através das quais são, todavia, estudadas as Literaturas Africanas, proporcionando um conjunto de perspectivações capazes de responder às solicitações que determinados textos literários parecem conter e apontar. A este propósito, merece salientar-se que:

\footnotetext{
${ }^{12}$ A este propósito, pense-se, por exemplo, nos volumes de contos Índicos Indícios I - Setentrião (2005) e Índicos Indícios II - Meridião (2005) ou ainda no romance O Olho de Hertzog (2010). Em ambos os casos a dimensão espacial surge como um paradigma narrativo crucial, apontando para um conjunto de relações transnacionais significativas.

${ }^{13} \mathrm{Ou}$, por outro lado, a proposta literária de Borges Coelho parece contribuir para reconfigurar a própria definição - conceptual e epistemológica - de contexto nacional.

${ }^{14}$ Entre os muitos contrapontos possíveis, pense, por exemplo, em autores como: Abdulrazak Gurnah, Abdourahman A. Waberi, Ananda Devi, Imraan Coovadia, Jean-Luc Raharimanana, Khal Torabully, Nuruddin Farah - entre outros - cuja obra literária é pautada por temas e sujeitos que podem ser lidos através de uma operacionalização crítica e conceptual do paradigma do Índico.
} 
Tal como todos os textos literários, também os romances africanos oferecem pistas que podem ser utilizadas para os ler e apreciar. Neste sentido, muitos romances teorizam-se a si próprios, instruindo-nos, através da gramática narrativa, sobre como os deveríamos ler com proveito. (George, 2010: 21; tradução minha)

Neste sentido, o contraponto entre a obra de M.G. Vassanji e João Paulo Borges Coelho proposto neste artigo surge em resposta às solicitações que os próprios textos parecem sugerir, sobretudo tendo em conta a dimensão espácio-temporal onde as duas narrações, em rigor, se inscrevem, proporcionando, deste modo, um conjunto de contactos, intersecções e proximidades que serão postas em diálogo através de uma leitura que pretende conjugar especificidades regionais e nacionais dentro de um horizonte contextual mais alargado tal como parece ser o do Índico.

\section{Leituras e Contrapontos. O Olho de Hertzog e The Book of Secrets}

History drifts about in the sands, and only the fanatically dedicated see it and recreate it, however incomplete their visions and fragile their constructs.

M. G. Vassanji, The Book of Secrets

Se encontrasse agora a rapariga, recuaria um pouco no tempo, pedir-lhe-ia ainda uma última história, a mais complexa de todas; não as costumeiras histórias em que se vão retirando véus até ficar desnudado por completo o acontecido, mas uma história nova, toda ela virada para adiante.

J.P. Borges Coelho, O Olho de Hertzog

Em vista do itinerário crítico que me proponho desenvolver, torna-se útil introduzir e contextualizar, ainda que brevemente, a obra dos dois autores considerados neste estudo.

A obra literária de João Paulo Borges Coelho (Moçambique) convoca algumas das questões mais centrais da história de Moçambique, propondo uma configuração do espaço-tempo moçambicano, sem dúvida, singular. Particularmente emblemática é a relação que surge entre narrativas históricas e representação literária, onde o projecto criativo do autor parece apontar para um conjunto de solicitações teóricas significativas no que concerne a relação entre história e memória, tempo passado e condição presente, configurando a escrita literária como um lugar matricial para refundar a relação entre ficção e realidade. A este propósito, como salienta Rita Chaves:

(...) incorporando no exercício da ficção o compromisso com um projeto que tangencia e se distingue daquele que move o historiador (...) atualiza uma concepção de literatura que não quer se confundir com a história, nem substituí-la no que ela tem de particular. Daí a sua capacidade de fundar outros mundos com 
que ajuda a revelar a complexidade do universo em movimento que é um traço do nosso tempo, em Moçambique e em outras latitudes (Chaves, 2008: 198).

Para além disso, o apelo a um imaginário espacial e cultural específico, tal como parece ser o do Índico, considerando ainda que só alguns dos títulos ${ }^{15}$ que constituem a obra literária produzida por Borges Coelho, torna-se crucial, apontando para uma reconfiguração contextual paradigmática, cuja abordagem permite reflectir em torno de um conjunto de temas e sujeitos inéditos no que diz respeito às questões que habitualmente marcam a literatura moçambicana. Portanto, o Índico a entender-se como "arena inter-regional emblemática" (Bose, 2006) configura-se como uma perspectivação conceptual e epistemológica alternativa para ler e situar a obra deste autor, oferecendo abordagens e problematizações significativas no que concerne às especificidades que caracterizam o contexto nacional e regional moçambicano ${ }^{16}$ convocados na escrita de Borges Coelho através de uma proposta literária que proporciona uma articulação crucial entre memórias privadas e narrativas históricas.

No que diz respeito à obra literária de M.G. Vassanji (Tanzânia-Quénia-Canadá), surge também uma configuração singular entre narrativas históricas e ficção, configurando o texto literário como um lugar de resgate de um conjunto de especificidades culturais e identitárias, sem dúvida, significativas. É sobretudo nas primeiras obras da produção literária do autor ${ }^{17}$ que o Índico parece destacar-se como tema e motivo emblemático, proporcionando um conjunto de solicitações cruciais que se prendem com a história da região da África oriental - por exemplo, da Tanzânia e do Quénia - e, sobretudo, com a história da comunidade indiana dentro de uma perspectivação temporal e espacial situada. Aliás, dentro desta perspectiva contextual específica, a obra de M.G. Vassanji proporciona uma articulação significativa acerca da relação entre história e escrita literária ou, melhor, entre narrativas públicas e privadas. Aliás, a este propósito Shane Rhodes afirma:

The Book of Secrets procura inscrever na história um sentido de mistério, de incompreensão, através de uma narrativa assombrada pela sua própria

\footnotetext{
${ }^{15}$ Pense-se, neste sentido, ao texto Crónica da Rua 513.2 (Borges Coelho, 2006) e aos dois volumes de contos Índicos Indícios I - Setentrião e Índicos Indícios II - Meridião (Borges Coelho, 2005). De se salientar o recurso à palavra "indício" que parece proporcionar um conjunto de solicitações críticas e conceptuais significativas. Aliás, a dimensão "indiciária” do Índico na literatura de Borges Coelho e também dentro dos discursos culturais e identitários em Moçambique representa uma hipótese de estudo de grande interesse crítico. Esta questão constitui uma das reflexões críticas que me encontro a desenvolver no âmbito do meu projecto de pós-doutoramento.

${ }^{16}$ Penso, por exemplo, nos romances O Olho de Hertzog (Borges Coelho, 2010) e Crónica da Rua 513.2 (Borges Coelho, 2006).

${ }^{17}$ Refiro-me a textos como: The Gunny Sack (Vassanji, 1989), Uhuru Street (Vassanji, 1990), The Book of Secrets (Vassanji 1996) e The In-between World of Vikram Lall (Vassanji, 2004).
} 
incapacidade de produzir respostas; o romance tenta incluir o-que-é-não-dito como parte do-que-é-dito, não de um ponto de vista necessariamente binário, mas sim como parte integrante do próprio conhecimento: cegueira e visão tornam-se, assim, componentes complementares. Como o mesmo Vassanji afirma, o mistério da romance imita "o mistério da vida" (...) Talvez a questão mais importante com a qual The Book of Secrets nos deixa seja aquela colocada por Feroz no princípio do livro, cuja irrefutabilidade assombra todo o romance: "O que é a história, senhor?" (Vassanji, 1998: 4). E com efeito, quem é dono da história? Quem precisa de história? De que forma, história e colonização coincidem? O que é um facto? O que é uma ficção? (Rhodes, 1998: 190; tradução e sublinhados meus)

Ora, os contrapontos entre a obra literária destes dois autores poderiam ser multíplices, proporcionando diferentes leituras e itinerários críticos. Dada a impossibilidade de uma análise detalhada das várias obras que poderiam ser postas em diálogo, procurarei reflectir em torno de algumas questões e estratégias que sobressaem como pontos de contacto significativos em vista de uma reflexão em torno da constelação crítica e conceptual entre história, memória e representação dentro de uma perspectiva operacional específica tal como a do Índico.

Em primeiro lugar sobressai, na produção literária dos dois autores, uma narração edificada a partir de uma relação seminal entre narrativas históricas e memórias privadas, onde a representação literária se destaca como um lugar de questionamento da História e, simultaneamente, de resgate de narrativas da memória, promovendo uma redefinição da relação entre presente e passado, ficção e realidade.

Considerando, por exemplo, as obras O Olho de Hertzog (Borges Coelho, 2010) e The Book of Secrets (Vassanji, 1996) ${ }^{18}$ uma dimensão crítica emblemática é sugerida principalmente pelo papel que formas de narração como o diário parecem desempenhar na construção dos dois romances, apontando para uma dimensão relacional entre público e privado, experiência e objectividade, sem dúvida, significativa.

No caso da obra de M.G. Vassanji, The Book of Secrets, a forma diarística não responde apenas a uma dimensão arqueológica da narrativa, mas desdobra-se nos diferentes

\footnotetext{
${ }^{18}$ Neste sentido, é importante sublinhar que o contraponto entre estas duas obras literárias não se fundamenta num critério de semelhança e, logo, não procura evidenciar analogias criativas ou temáticas, remetendo para um conceito crítico - o Índico - que, por esta lógica, seria definível em termos de homogeneidade. Ao contrário, o diálogo entre os textos pretende, antes de mais, esboçar itinerários críticos que, sem abdicar das especificidades históricas e contextuais convocadas pelos textos, apontem para leituras alternativas e, simultaneamente, situadas das representações literárias e dos seus significados, articulando uma reflexão em torno de um paradigma epistemológico e conceptual complexo tal como o do Índico.
} 
tempos e planos da narração, destacando-se como uma configuração diegética e conceptual emblemática. Neste sentido, o "Livro dos Segredos", constituído pelo Diário de Alfred Corbin, Oficial do Império Britânico na África Oriental ${ }^{19}$, é apenas o ponto de partida para desvelar outros segredos, onde a intersecção entre narrativas da memória e $\mathrm{H} /$ história se torna crucial, sobretudo no que diz respeito às estratégias criativas que pautam a própria construção literária. Por outras palavras, como afirma o mesmo autor:

Em The Book of Secrets (...) não se trata apenas da questão da história "filtrada" por uma pessoa, mas também tem a ver com a história de um dado momento. Porque, sabes, a história é um acaso de tempo e pessoas. (...) Em The Book of Secrets há o diário, o livro dos segredos, mas há também o romance produzido pelo autor. A história é um jogo entre todos estes objectos: o criado e o que cria, o real e o imaginado. Por outras palavras, o narrador e o historiador jogam, ambos, uma espécie de jogo com a história. Aliás, a ideia do livro como um jogo, um jogo entre coisas, é muito importante para mim. A escrita torna-se assim um esquema [a gamesmanship], uma estratégia para contornar as próprias regras do jogo. (Rhodes, 1997: 108; tradução minha)

No que diz respeito à obra de Borges Coelho, O Olho de Hertzog, as chamadas narrativas privadas desempenham um papel fundamental do ponto de vista da construção do romance, apontando para um conjunto de solicitações significativas que pautam a relação entre narração literária e testemunho. Para além de um enredo que se vai construindo e desenvolvendo à medida que cada personagem enuncia a própria história ${ }^{20}$, o Diário do General Von Lettow-Vorbek - comandante do exército Alemão no Tanganica, durante a primeira Guerra Mundial,$-{ }^{21}$ ou ainda $O$ Livro da Dor de João Albasini - obra póstuma de carácter autobiográfico - são apenas algumas das narrativas privadas que informam a narração literária proposta pelo autor neste texto, proporcionando uma articulação entre memória, história e representação, sem dúvida, singular.

Em geral, a fisionomia narrativa que parece caracterizar estes textos aponta, de imediato, para um paradigma crítico pós-moderno tal como o da metaficção histórica, onde a desconstrução da relação entre representação ficcional e realidade se torna matricial.

\footnotetext{
${ }^{19}$ O diário fundamenta-se nos documentos: "Confidential Memoranda for Provincial Commissioners and District Commissioners,” (1910) do Governador E. P. C. Girouard (Vassanji, 1994: 339).

${ }^{20}$ Relativamente a esta dimensão de enunciação e ambiguidade que caracteriza este romance de Borges Coelho, veja-se Brugioni 2012.

${ }^{21}$ Paul Von Lettow-Vorbek (1923) As minhas memórias na África Oriental. Évora: Minerva.
} 
A metaficção historiográfica relembra-nos, desconfortavelmente, que, enquanto os factos ocorreram no passado real e empírico, nomeamos e constituímos estes eventos como factos históricos através de narrativas seleccionadas e posicionadas. $\mathrm{E}$ até, de uma forma ainda mais básica, conhecemos apenas aqueles eventos passados que possuem uma inscrição discursiva, cujos rastos são visíveis no presente. (Hutcheon, 1988: 97; tradução minha)

Todavia, o que caracteriza os textos de Vassanji e Borges Coelho parece sugerir um conjunto de solicitações críticas ulteriores, sobretudo uma vez que a arquitectura narrativa que pauta estas escritas é posta em contraponto com uma dimensão contextual e relacional específica, proporcionando uma relação crucial entre tempo e espaço. A este propósito, tal como afirma Nazir Can:

O jogo poético que [João Paulo Borges Coelho] propõe assenta, sobretudo, na combinação quase caricatural entre o "pequeno" (quotidiano) e o "grande" (factos históricos), o primeiro virtuoso por excelência, criando um eco ou um profundo efeito de semelhança no/do segundo; isto é, multiplicando-o, segredando-o, iluminando-o, quase nunca o dizendo literalmente. $\mathrm{E}$ isto porque a obra literária de JPBC caracteriza-se por esta busca de verosimilhança (ou por aquilo que Francisco Noa denomina “(...) o espaço profícuo da probabilidade” - 1997, 3) entre as histórias anódinas do homem comum e a História. (Can, 2011: 13)

Em primeiro lugar, a relação que se vai estabelecendo entre História, histórias e testemunhos, ou ainda entre objectividade e experiência (Sarlo, 2005) aponta para uma redefinição conceptual e epistemológica cujas implicações são relevantes tendo em conta "a crise de memória" (Terdiman, 1993) e logo "o sentido de desarticulação orgânica entre passado e presente" (idem) que parecem caracterizar sujeitos, situações e contextos que pautam estes textos literários.

No entanto, os dois romances parecem sugerir uma fisionomia singular que diz respeito às narrativas individuais e da memória que, em ambos os textos, apontam para processos criativos, caracterizados, em primeiro lugar, pela sua feição inevitavelmente incompleta e ambígua. Aliás, o sentido de mistério e ambiguidade que caracterizam diferentes níveis e aspectos da narração desenvolvida nos dois romances, colocam estas escritas numa dimensão fenomenológica e semântica que se situa "para além da História”, configurando o texto literário como um lugar onde a relação entre presente e passado, história e memória não pretende ser resolvida, mas antes permanecer acessível e, logo, em constante questionamento.

No caso de The Book of Secrets de M.G. Vassanji, a intersecção entre narrativas históricas e memórias individuais configura o texto como uma mise en abyme, 
desconstruindo uma relação antitética entre factos reais e ficção e, sobretudo, problematizando a dimensão subjetiva da memória, o processo criativo que a caracteriza e, logo, a sua feição inevitavelmente inacabada. A este propósito importa salientar que a narração desenvolvida em The Book of Secrets parte de um pressuposto que o autor reconhece explicitamente e que se prende com um sentido de ausência de história que caracteriza, por exemplo, a comunidade indiana da África Oriental ${ }^{22}$ cuja memória é edificada, no romance, a partir do diário do oficial britânico Alfred Corbin, lido e "completado" pelo narrador/protagonista Pius Fernandes, professor de história - indiano de origem goesa -, a quem cabe a tarefa de decifrar os segredos do livro.

They called it the book of our secrets, kitabu cha siri zetu. Of his writer they said: He steals our souls and lock them away; it is a magic bottle, this book, full of captured spirits; see how he keeps his eyes skinned, this muzungu, observing everything we do; look how meticulously this magician with the hat writes in it, attending to it more regularly than he does to nature, with more passion than he expends on a woman. (...) They were only partly right, after all those wazes - the ancients - who voiced wonder filled suspicion at the book and its writer, the allpower European whiteman administrator who has appeared in their midst to govern. They not know that this muzungu first and foremost captured himself in his bottle-book; and long after it left his side - taking part of him wit it - it continued to capture other souls and their secrets and dictate its will upon them. Even now it makes protagonists of those who would decide its fate. Because it has no end, this book, it ingests us and carries us with it, and so it grows. (Vassanji, 1996: 2)

No que diz respeito a O Olho de Hertzog de João Paulo Borges Coelho, surge de imediato uma relação entre representação e factos verídicos onde a qualidade da História apontada ou, melhor, resgatada pelo texto e a sua relação com o chamado presente é essencial. Aliás, as personagens que habitam a narração e os seus cenários representam sujeitos, lugares e circunstâncias cruciais da chamada História moçambicana e, mais em geral, da África Austral; no entanto, não é a verossimilhança o traço mais emblemático da relação entre história e realidade que o romance de Borges Coelho edifica. Aliás, a este propósito, como realça o próprio autor:

A cultura histórica estabelecida é aquela que torna palatável e enriquece uma versão da história pré-existente. Como se esta última fosse uma coluna vertebral e o suposto papel da história não fosse desmontar as vértebras mas, antes, limitar-se a

\footnotetext{
${ }^{22}$ A este propósito, veja-se a entrevista de M.G. Vassanji in WASAFIRI, nº 13, 1991. (Nasta, 1991: 19-21).
} 
trazer carne para "encher" os ossos. Como se os episódios silenciados, autosilenciados, nunca tivessem existido. Não há história sem o permanente questionamento dos seus fundamentos. A actividade da história é indissociável da reflexão epistemológica. Não é o conteúdo das narrativas dominantes que eu questiono, mas a metodologia por detrás da sua construção. (Borges Coelho, 2010a)

É ainda por via desta estratégia narrativa que a dicotomia entre verdade e ficção é ultrapassada, configurando o texto literário como um lugar de resgate da História e da memória e, logo, como um espaço de enunciação de universos possíveis, onde, como afirma Rita Chaves:

Essa ampliação do eixo sobre o qual se organiza a matéria narrada combina-se a procedimentos transfiguradores da realidade, assumindo-se a ficcionalização como caminho para a composição da estória de um grupo devidamente situado em seu lugar, no campo geográfico e no social. (Chaves, 2010: 95)

Aliás, a questão referente à dimensão epistemológica que se prende com a prática de construção de uma cultura histórica representa um desdobramento crítico matricial sugerido pelo texto, apontando para uma aparato conceptual onde categorias como público/privado, história/memória, objectividade/testemunho são cruciais, proporcionando uma reflexão teórica e epistemológica complexa acerca da escrita literária e dos seus desdobramentos numa dimensão cultural situada.

\section{Em jeito de conclusão}

Em primeiro lugar, a escrita de M.G. Vassanji e João Paulo Borges Coelho configura-se como uma proposta literária que parece refundar a relação entre tempo e espaço, público e privado, memória e história, procurando questionar as dicotomias através das quais são lidos sujeitos, contextos e situações. Em geral, as implicações que estas escritas parecem possuir numa dimensão contextual situada tornam-se, sem dúvida, significativas especialmente no que concerne a relação entre representação literária, História/histórias e problemáticas socioculturais e políticas da contemporaneidade. A reflexão complexa sugerida pelos textos em torno da relação entre memória e História, numa perspectiva que pretende antes questionar uma visão consensual e celebratória das narrativas históricas, entrelaçando-as com memórias e testemunhos individuais, aponta para uma prática de representação singular e emblemática que sugere uma dimensão epistemológica relevante, configurando o espaço literário como um lugar onde narrativas, memórias e testemunhos se tornam "públicos", isto é acessíveis, partilhados e, logo, questionáveis. Salientando uma manifesta "inevitabilidade do passado" (Sarlo, 2005: 9), as propostas literárias destes dois autores configuram-se 
como representações que, ainda parafraseando Beatriz Sarlo, não pretendem resolver as problemáticas da $\mathrm{H}$ /história e da memória (2005), mas sim articular presente e passado através de uma relação complexa, cuja fisionomia potencial, fragmentária e, sobretudo, inacabada é emblematicamente ilustrada no espaço literário, fornecendo um conjunto de solicitações críticas e teóricas, sem dúvida, originais e significativas. Aliás, os textos considerados convocam solicitações cruciais que apontam para a problematização de um conjunto de questões contextuais específicas, proporcionando múltiplas possibilidades de reflexão em torno dos paradigmas que pautam a crítica humanística e, mais especificamente, o campo crítico das Literaturas Africanas.

Destaca-se a dimensão teórica e epistemológica sugerida pelo recurso ao que foi definido como "paradigma do Índico". Tal como salientado por vários teóricos dos chamados Indian Ocean Studies, uma abordagem da dimensão cultural, histórica e social deste paradigma espaço/temporal específico proporciona o aparecimento de um conjunto de desdobramentos críticos e conceptuais emblemáticos para redefinir temas, sujeitos e relações que pautam estas representações literárias. Por outras palavras, ambos os textos analisados propõem uma complexificação emblemática das relações que se vão estabelecendo entre sujeitos e situações dentro de uma perspectiva temporal e política que se situa, por exemplo, na chamada colonialidade, convocando, simultaneamente, eventos marcantes do que vem sendo definido como grande narrativa europeia - a primeira guerra mundial na África oriental alemã, a missão civilizadora que caracteriza ideologicamente a colonização de África, entre outras Particularmente significativa parece a problematização das relações raciais e identitárias cuja articulação se desdobra num quadro contextual dificilmente observável por via de paradigmas de matriz binária, tais como branco/negro, colonizado/colonizador, colono/indígena, africano/europeu, entre outros, e onde a dimensão social, política e cultural do Índico se configura como tema e motivo central para a uma problematização situada em torno destas articulações conceptuais e epistemológicas.

No entanto, não tendo aqui a possibilidade de me deter de uma forma mais pormenorizada sobre as hipóteses de reflexão crítica e contextual que uma leitura aprofundada destes textos poderia facultar, pretendo apenas sublinhar a necessidade de repensar os aparatos teóricos e, logo, os itinerários epistemológicos que configuram a crítica às Literaturas Africanas, proporcionando, deste modo, abordagens e leituras que vão de encontro à originalidade dos desafios postos por certos textos literários contemporâneos e, logo, promovendo o surgir de cartografias críticas e constelações 
teóricas alternativas e indispensáveis para repensar os significados das representações literárias no mundo contemporâneo.

Concluindo, dentro de um amplo conjunto de questões que a leitura e o contraponto entre estas escritas parece colocar, gostaria de destacar apenas algumas interrogações, cuja pertinência me parece particularmente significativa pois a sua articulação deixa em aberto itinerários críticos e epistemológicos inéditos e ainda por desenvolver.

Em primeiro lugar, sobressai uma interrogação que se prende com as cartografias que caracterizam o cânone crítico das chamadas Literaturas Africanas. Aliás, a escassa consolidação do que neste estudo foi definido como "paradigma do Índico" para uma abordagem destas representações literárias será, porventura, determinada pela relativização de uma relação de origem colonial, veiculada pela partilha linguística que parece subentendida pela definição do Índico como "paradigma para um transnacionalismo do Sul Global” (Hofmeyr, 2007)? Ou melhor, em que medida, a marginalização das relações - históricas, sociais e culturais - com a Europa poderá ser considerada como um elemento de inviabilização no que concerne o surgir e o consolidar-se de uma definição transnacional e heteroglóssica de grande originalidade e interesse epistemológico tal como a de Literaturas do Índico?

Em segundo lugar, surge uma questão que se prende com determinadas especificidades propostas pelas próprias representações literárias onde uma problematização sui generis em torno de paradigmas como identidade - cultural, nacional, etc. - raça, colonialidade, situação pós-colonial, entre outros, parece antes desconstruir alguns dos aparatos teóricos mais consolidados relativamente à própria abordagem crítica das Literaturas Africanas. Por outras palavras, se a literatura é, por norma, encarada como uma prática cultural concorrente à construção de uma identidade nacional pós-colonial - onde a relação de oposição entre colonial é pós-colonial é crucial-, em que medida as escritas que ilustram uma transição ambígua ou, ainda, uma dispersão identitária (Noa, 2012) significativa poderão ser lidas e observadas a partir do paradigma crítico da literatura nacional? Ou, ainda, será que as próprias solicitações contidas nestas escritas apontam para uma perspectivação crítica de matriz pós-nacional - não de dimensão celebratória tal como parece ser a lusófona - ou, melhor, transnacional onde a visão individual esbate uma definição comunitária - isto é, partilhada - destas representações?

São estas, a meu ver, algumas das perguntas a partir das quais uma reflexão crítica deveria mover, proporcionando, deste modo, itinerários críticos e epistemológicos 
capazes de promover uma mais ampla redefinição das práticas de representação literária e do seu campo semântico e operacional.

\section{Referências bibliográficas}

Ahmad, A. (1992). In Theory: Classes, Nations, Literatures. London and New York: Versus.

Appadurai, A. (1996). Modernity at Large: Cultural Dimensions of Globalization. Minneapolis-London: University of Minnesota Press.

Borges Coelho, J.P. (2010a). A Literatura e o léxico da pós-colonialidade. Uma Conversa com João Paulo Borges Coelho. Diacrítica - Dossier de Literatura Comparada (24) 3, 427-444.

-- (2010) O Olho de Hertzog. Lisboa: Leya.

-- (2006) Crónica da Rua 513.2. Lisboa: Caminho.

-- (2005) Índicos Indícios I - Setentrião. Lisboa: Caminho.

-— (2005) Índicos Indícios II - Meridião. Lisboa: Caminho, 2005.

Bose, S. (2006). A Hundred Horizons: The Indian Ocean in an Age of Global Imperialism. Cambridge, Mass.: Harvard University Press.

Braudel, F. (1985). La Méditerranée, vol. 1: L'espace et l'histoire, vol. 2: Les homes et l'héritage. Paris: Flammarion.

Brugioni, E. (2012a). Contiguidades Ambíguas: Crítica Pós-colonial e Literaturas Africanas. In Leite, A. M., Chaves, R. \& Apa, L. (Orgs.) Nação e Narrativa PósColonial. (pp. 379-394) Lisboa: Edições Colibri.

- (2012) Resgatando Histórias. Épica moderna e pós-colonialidade. Uma leitura de O Olho de Hertzog de João Paulo Borges Coelho. In Brugioni, E., Passos, J., Sarabando A. \& Silva, M-M. (Orgs.). Itinerâncias. Percursos e Representações da Póscolonialidade | Journeys. Postcolonial Trajectories and Representations. (pp.391-404) .Vila Nova de Famalicão: Húmus Edições-CEHUM.

Brugioni, E. \& J. Passos (Orgs.) (2013) Dossier "Narrando o Índico" in Diacrítica Literatura, 27 (3). Vila Nova de Famalicão-Braga: Húmus Edições-CEHUM.

Can, N. (2011). História e ficção na obra de João Paulo Borges Coelho: discursos, corpos, espaços. Tesi doctoral. Universitat Autònoma de Barcelona Facultat de Lletres Departament de Filologia Espanyola Gener de 2011.

Chaundhury, K.N. (1990). Asia before Europe: Economy and Civilization of the Indian Ocean from the rise of Islam to 1750, Cambridge Eng. Cambridge UP. 
Chaves, R. (2008). Notas sobre a Ficção e a Histária em João Paulo Borges Coelho. In Calafate Ribeiro, M. \& Meneses, M.P. (Orgs.) Moçambique: das palavras escritas. (pp. 187-198), Porto: Edições Afrontamento.

Falconi, J. (2012). Literaturas Africanas, língua portuguesa e pós-colonialismos. In Brugioni, E., Passos, J., Sarabando A. \& Silva, M-M. (Orgs.). Itinerâncias. Percursos e Representações da Pós-colonialidade | Journeys. Postcolonial Trajectories and Representations. (pp. 203-218), Vila Nova de Famalicão: Húmus Edições-CEHUM.

-- (2008) Utopia e conflittualità. Ilha de Moçambique nella poesia mozambicana contemporanea. Roma: Aracne.

Fawaz, L.T. \& Bayly C.A. (Eds.) (2002). Modernity and Culture: From the Mediterranean to the Indian Ocean. New York: Columbia University Press.

Garuba, H. (2009). The Critical Reception of the African Novel. In Irele, F. A. (Ed.) The Cambridge Companion to the African Novel, (pp. 243-262), Cambridge: Cambridge University Press.

George, O. (2009). African Novels and the Question of Theory. In Gaurav, D. (Ed.) Teaching the African Novel. (pp.19-36), New York: Modern Language Association of America.

Gramsci, A. (2007). Quaderni del Carcere. Edizione critica a cura dell'Istituto Gramsci. Torino: Einaudi.

Gupta, P., Hofmeyr, I. \& Pearson, M. (Eds.) (2010). Eyes Across the Water. Navigating the Indian Ocean. Unisa Press \& Penguin India.

Hall, S. (1990). Cultural Identity and Diaspora. In Rutheford, J. (Ed.) Identity, Community Culture, Difference. (pp. 222-223), London: Lawrence and Wishart.

Hofmeyr, I. (2007). The Black Atlantic meets The Indian Ocean: Forging New Paradigms for transnationalism for the Global South. Literary and Cultural Perspectives. Social Dynamics. A Journal of African Studies, 33 (2), 3-32.

Hutcheon, L. (1998). A Poetics of Postmodernism: History, Theory, Fiction. New York: Routledge.

Kearney, M. (2004) The Indian Ocean in World History . London: Routledge.

McPherson, K. (1993). The Indian Ocean: A History of People and the Sea. Delhi: Oxford University Press.

Moorthy, S. \& A. Jamal (Eds.) (2010) Indian Ocean Studies: Cultural, Social, and Political Perspectives. New York: Routledge.

Nasta, S. (1991). Interview: Moyez Vassanji with Susheila Nasta. WASAFIRI, 13, 19-21.

Noa, F. (2012). Oceano Índico e a dispersão identitária: o caso de Moçambique. Comunicação apresentada na Conferência Internacional OS INTELECTUAIS AFRICANOS FACE AOS DESAFIOS DO SEC. XXI Em Memória de Ruth 
First/Celebração dos 50 anos da UEM. Centro de Estudos Africanos da Universidade Eduardo Mondlane, Maputo, 28 e 29 de Novembro (texto inédito)

Parry, B. (2009). The Institutionalisation of postcolonial studies. In Lazarus, N. (Ed.) The Cambridge Companion to Postcolonial Literary Studies. (pp. 66-82), Cambridge: Cambridge University Press.

Pearson, M. N. (2011). History of the Indian Ocean: a Review Essay. WASAFIRI, 26: (2), 78-99.

--(2003) The Indian Ocean. London: Routledge.

Rohdes, S. (1998). Frontier Fiction: reading Books in M.G. Vassanji's 'The Book of Secrets'. ARIEL: A review of International English Literature, 29 (1), 179-193.

--M.G. Vassanji: an interview. Studies in Canadian Literature, 22 (2), 105-17.

Said, E. W. (2004). Humanism and democratic criticism. New York: Palgrave.

Sanches, M. R. (2007). Reading the Postcolonial: History, Anthropology, Literature and Art in a 'Lusophone Context'. In Medeiros, P. de (Ed.) Postcolonial Theory and Lusophone literatures. (pp. 29-148). Utrecht: Portuguese Studies Centre.

Sarlo, B. (2005). Tiempo Pasado: Cultura de la Memoria y Giro Subjetivo - Una Discusión. Buenos Aires: Siglo Veintiuno Editores.

Terdiman, R. (1993). Present Past. Modernity and the Memory Crisis. Ithaca and London: Cornell University Press.

Lettow-Vorbek, P. von. (1923). As minhas memórias na África Oriental. Evora: Minerva.

Vassanji, M.G. (2004). The In-between world of Vikram Lall. London: Canongate.

- (1996) The Book of Secrets. London: Picador.

-- (1990) Uhuru Street. Oxford: Heinmann.

- (1989). The Gunny Sack. Oxford: Heinmann.

Vergès, F. (2003). Writing on Water: Peripheries, Flows, Capital, and Struggles in the Indian Ocean. Positions: East Asia Cultures Critique. Special issue, The Afro-Asian Century, 11 (1), 241-57.

Elena Brugioni é Doutorada em Literaturas Africanas de Língua Portuguesa e Investigadora em Pós-doutoramento no Centro de Estudos Humanísticos - CEHUM. As suas áreas de investigação passam pelas Literaturas Africanas, Estudos do Índico [Indian Ocean Studies] e Estudos Pós-coloniais. Desde 2010 desenvolve o projecto de Pós-doutoramento financiado pela Fundação para a Ciência e a Tecnologia (Programa Operacional Potencial Humano e Fundo Social Europeu) "Provincianizando o Cânone. O questionamento das 'grandes narrativas' europeias em literaturas homoglotas" [SFRH/BPD/62885/2009]. É membro do GAPS - Grupo de Pesquisa em Artes, Género \& estudos Pós-coloniais do Centro de Estudos Humanísticos e docente no Programa Doutoral em Modernidades Comparadas (CEHUM/ILCH) da Universidade do Minho. ebrugioni@ilch.uminho.pt 